\section{Chemetall Opens}

\section{New Production Facility in the USA}

$T_{\text {he }}^{\text {he }}$ he newly opened Chemetall production facility in Blackman Township, USA, is one of the biggest surface treatment facilities in the world. Chemetall has invested around $\$ 25$ million in this manufacturing plant, which will cover approximately 20,000 square metres to house manufacturing, and warehousing operations as well as a physical testing laboratory. Almost one thousand Chemetall products and processes will in future be produced at the site for applications in surface treatment,

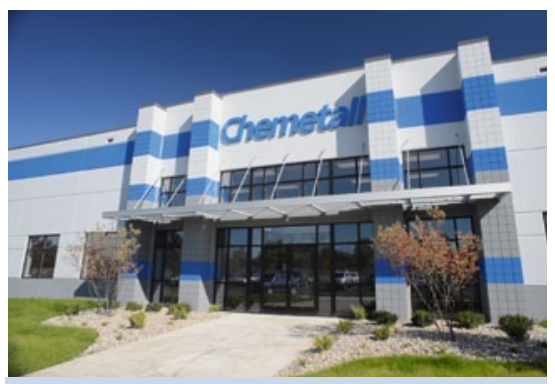

The main building of the new Chemetall production facility in Blackman Township, USA

metal fabrication, surface cleaning and metal processing. According to the company, the new facility fulfils the highest environmental and safety standards. "With this investment in Blackman Township we will further expand our surface treatment business in the NAFTA region. We are committed to setting equally high standards around the globe with regard to superior quality for our customers and a low carbon footprint" said Joris Merckx, President of Chemetall. At the new plant, a semi-automated waste treatment system has been installed to reduce process waste water by 90 percent. Automation advancements, including bulk material handling systems, mixing vessels and packaging lines, have also been incorporated into the Blackman Township facility to increase productivity as well as to improve product yield and quality for customers.

\section{New Regional Vice President at Enthone Europe}

Thomas Ahrens has been appointed Regional Vice President, Enthone Europe. Before joining Enthone, Ahrens held several senior leadership roles in a variety of industries, and most recently he was the interim CEO of MCS Technologies $\mathrm{GmbH}$, where he was instrumental in restructuring the business. Prior to this, he worked for the Total Group for fifteen years. He spent over six years as the global vice president of operations at its direct subsidiary, Atotech. Ahrens will be based at the company's European headquarters in Langenfeld, Germany.

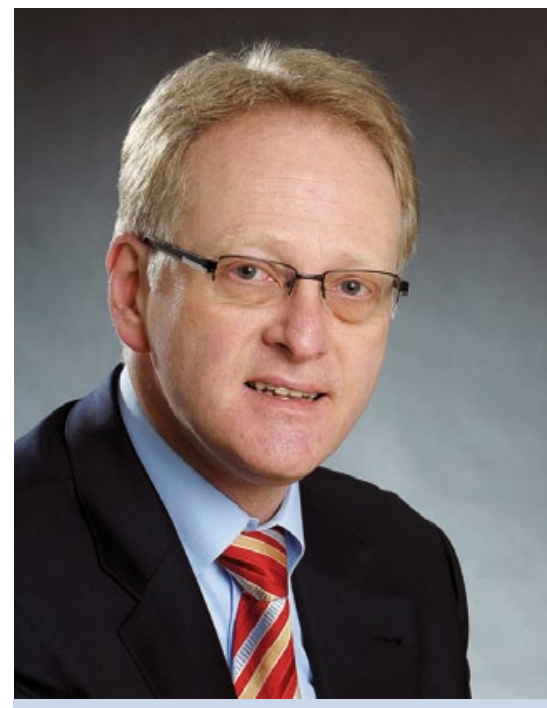

Thomas Ahrens is the new Regional Vice President of Enthone Europe

\title{
7,000th Dürr Painting Robot Operates in China
}

A fter a positive experience with several Dürr paint shops already supplied, the Chinese joint venture SGM has ordered two more, one for the Norsom III plant in spring 2012 and now as follow-up project in Wuhan. In this identical plant, the 7,000th painting robot from Dürr will go into operation. As the general contractor, Dürr is building an energy-saving and resource-saving production facility with the latest technology in Wuhan. Interior and exterior painting in the topcoat area is performed fully automatically by 86 robots. On each line, each body is cleaned with emu feathers before the painting process takes place. The base coat and clear coat are applied by a rotary atomiser (EcoBell2). When used for interior painting, this atomiser achieves a higher application efficiency than an ordinary atomiser and additionally provides significant material savings. The paint booth system EcoDryScrubber saves up to 60 percent of energy in the painting booth. The combination of dry separation and fully automatic paint application on the interior and exterior leads to a significant reduction in operating costs. This affects energy consumption as well as the consumption of paint. In addition to that, synergy effects from the predecessor project could be realised.

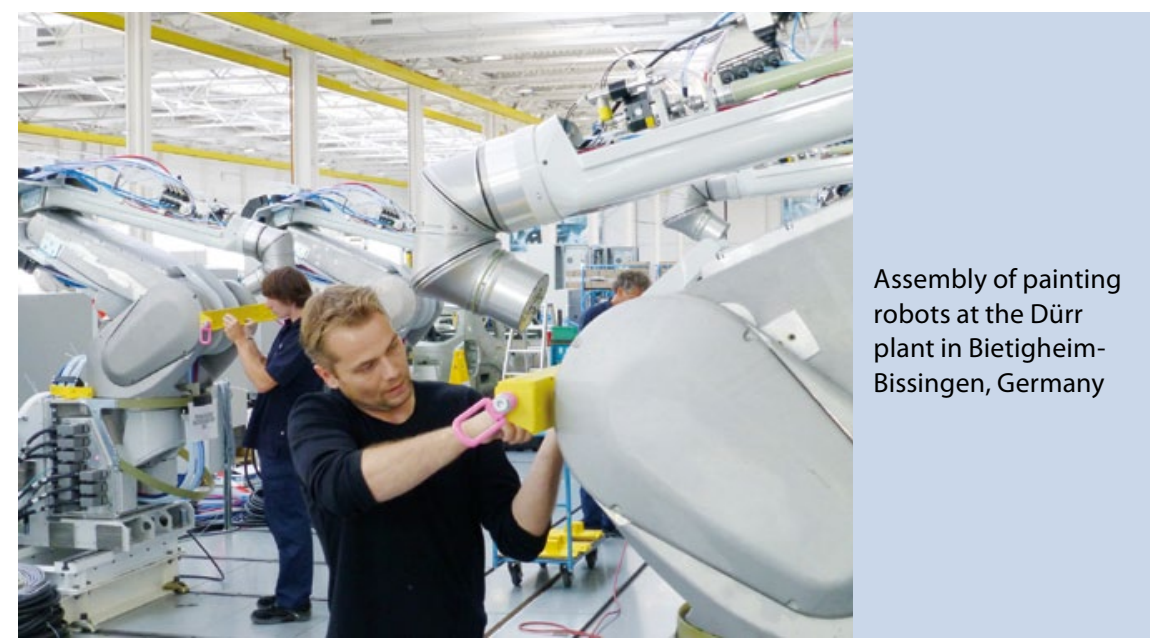

